\title{
17
}

\section{Ten steps to success in integrative research projects}

\author{
Bärbel Tress ${ }^{\#}$, Gunther Tress ${ }^{\#}$ and Gary Fry ${ }^{\# \#}$
}

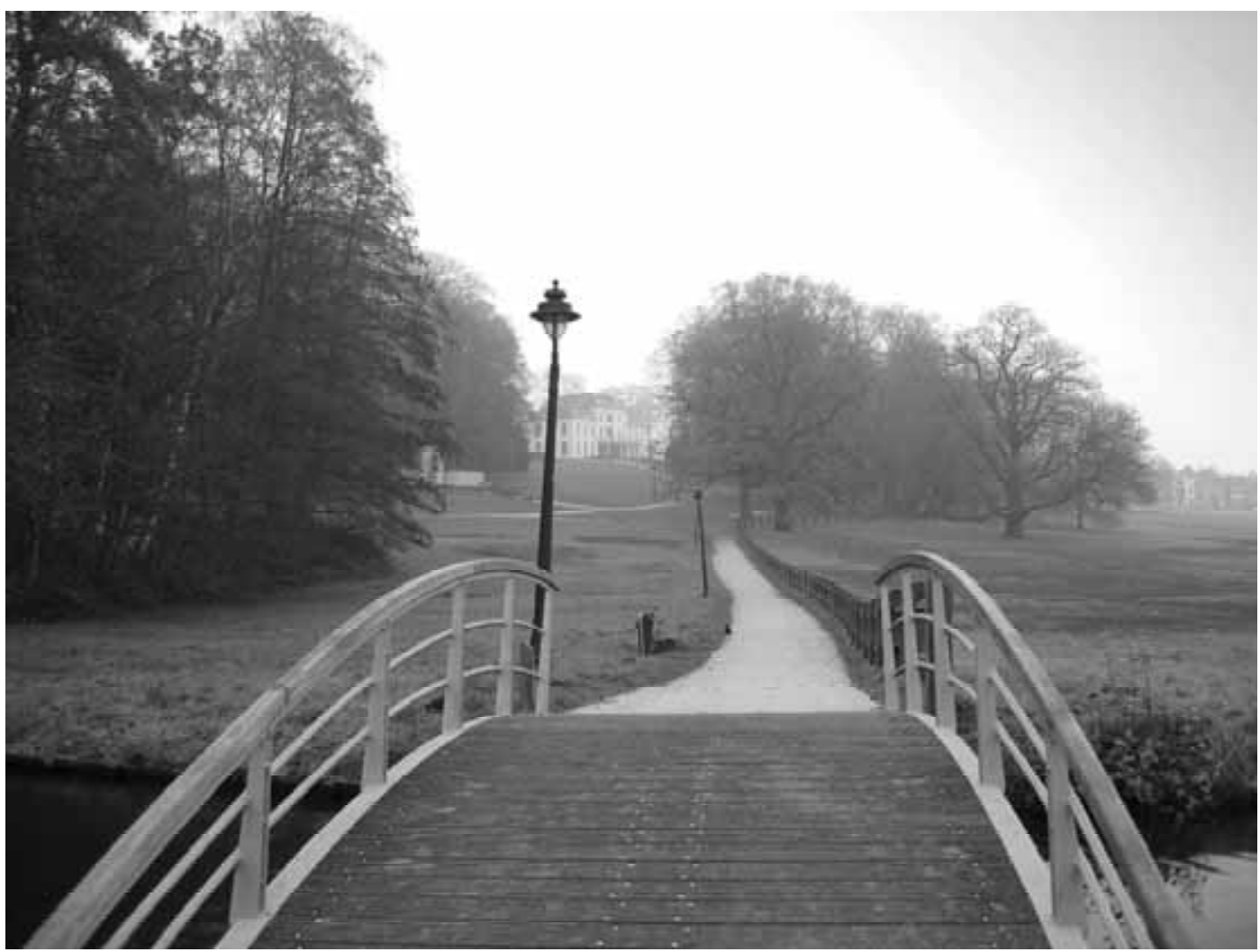

\begin{abstract}
Research in the INTELS project has revealed that many integrative (= interdisciplinary and transdisciplinary) landscape projects frequently face similar challenges. There are, however, few guidelines available to help projects avoid common problems. In this chapter, we present what we consider the ten most important steps towards successful integrative research projects. We define successful projects as those that reach integration and project goals, produce tangible outcomes, contribute to progress in integrative research and provide positive experiences for their participants. In order to reach success, we recommend that projects are specifically organized to reach integration through the development of an Integration Implementation Plan. Projects should identify a common research question and clear project goals; these will identify the relevant disciplinary expertise needed. Because

\footnotetext{
${ }^{\#}$ Land Use Planning Group, Department of Environmental Sciences, Wageningen University, Generaal Foulkesweg 13, 6703 BJ Wageningen, The Netherlands. E-mail: tress@tress.cc, http://www.tress.cc \# Institute of Landscape Planning, Norwegian University of Life Sciences, P.O. Box 5029, N-1432 Ås, Norway. E-mail: gary.fry@umb.no
} 
integrative projects have a higher time demand, we suggest adopting time management practices and the allocation of realistic time budgets, especially at the beginning of projects. Strong leadership plays a crucial role in the success of integrative research and requires a high level of interpersonal skills as well as research credibility. Frequent meetings among the participants and the support of the wider research environment also help to achieve success. Project teams need to arrive at a common understanding and definition of the integrative concept and prepare for overcoming epistemological hurdles by acquiring basic skills in the disciplines involved. We recommend that projects are planned for tangible project outcomes/deliverables, particularly in terms of scientific publications. A publication plan identifies target groups, specifies media and journals, lists responsible authors, arranges writing meetings and sets milestones and submission dates. We conclude with the suggestion that projects agree on evaluation criteria and use these to assess the project and its outcomes on a regular basis. Integrative projects can learn from past experiences, and we therefore encourage participants to report experiences from integrative projects. These experiences contain valuable knowledge that will, over time, lead to more successful integrative research.

Keywords: epistemology; integration; leadership; participants; project goal; project outcome; publication; research assessment; research environment; time demand

\section{Introduction}

In the past three years, we have carried out intensive research on integrative (= interdisciplinary and transdisciplinary) landscape projects. This research revealed that projects frequently face the same or similar challenges. However, as problems are seldom mentioned in project reports or publications, integrative landscape projects cannot build on these experiences or learn from each other. When presenting our findings on difficulties and challenges in integrative projects at international conferences and meetings, researchers frequently ask us for strategies to achieve successful integration in projects. The objective of this chapter is to provide information on what we feel are the most important aspects that can help projects achieve success in integrative research. We start by describing common problems in integrative projects, and suggest ways to cope with them. The key steps identified cover all stages of research projects from project planning and management, selecting relevant epistemology, teamwork, communication, project atmosphere and products.

By successful integrative projects we understand projects that have

a) reached integration

b) reached project goals and produced the planned outcomes/deliverables

c) contributed to progress in the field of integrative research

d) provided a positive experience for the project participants.

The framework and basis for our solutions and suggestions are based on the findings of the INTELS project (Interdisciplinarity and Transdisciplinarity in European Landscape Studies, see http://www.intels.cc). The INTELS project gathered data from 19 qualitative interviews with funding bodies, project leaders and participants involved in integrative projects on European landscapes (Tress, Tress and Fry 2005), as well as an international web survey of 235 researchers involved in integrative landscape research projects. In addition, we collected information from a literature review, reports and written descriptions of integrative research programmes. Although our empirical data are derived from the broad field of landscape research, 
we have documentation from other research fields that reveals similar challenges. We therefore believe that the key steps to success presented here will also be applicable to other fields of research.

Most challenges in integrative projects are related to the core task of reaching integration among different academic disciplines. By integration we understand the fusion of disciplinary knowledge with that from other disciplines. As a result of the integration process, new knowledge arises (e.g. in the form of a new theory or method) that cannot be assigned to a particular discipline, but is a joint product of the interdisciplinary or transdisciplinary effort.

Our suggestions address integrative projects at different organizational and management levels, from the university/institutional environment to the individual researcher. The target groups are, accordingly, research managers and directors, project leaders and researchers, including $\mathrm{PhD}$ students. Cooperation and communication are crucial in integrative research teams, and most of the suggested steps will only contribute to achieving success if they are discussed and implemented by the whole project team. We also stress the importance of the planning period and early project phase of integrative projects. In this period many decisions have to be taken that determine the success or failure of a project. Mistakes made at this stage can only be straightened out with great effort later in the project. Early planning and anticipation of the challenges that can appear are cornerstones to success. Figure 1 presents an overview over the challenges facing integrative research projects. The following key steps present strategies to cope with the respective challenges. After each section we suggest concrete actions towards success.

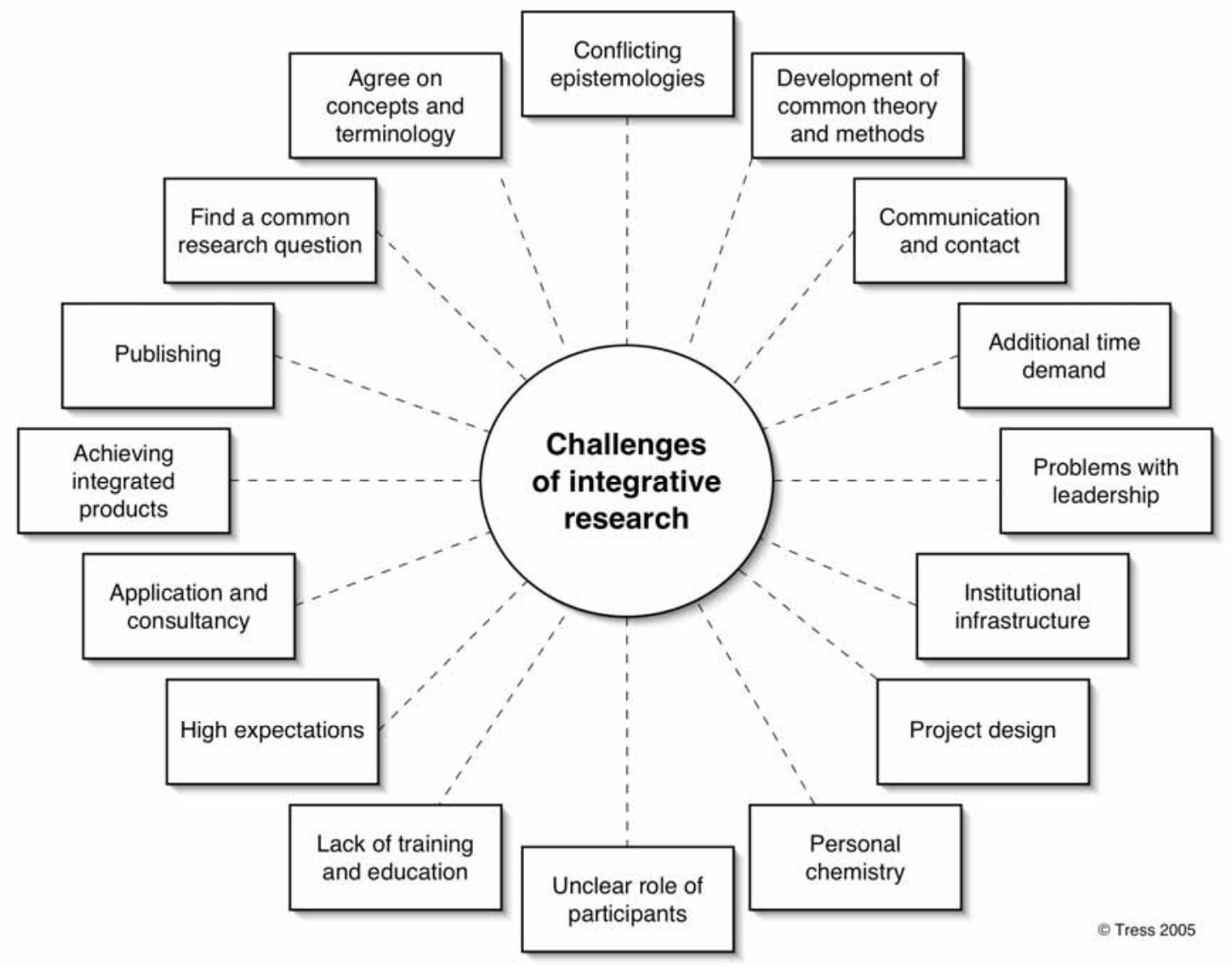

Figure 1. Overview of the challenges of integrative research projects 


\section{Step 1: Organize integration}

\section{Make integration a part of the project}

Integration does not come automatically when bringing different disciplines together. Therefore, achieving integration should be seen as an integral part of a project that needs to be organized. Projects that develop specific measures to facilitate integration are more likely to be successful. In contrast, if no action towards reaching integration is taken, then projects have a high risk of ending up as a collection of disciplinary efforts. We recommend starting integration from the very beginning of an integrative project, which is the phase of planning and proposal writing.

\section{Choose integrative project design}

When designing an integrative project, a project group should choose an organizational structure that is able to foster integration. In this sense we suggest setting up the project with an integrative project design, and avoiding a parallel project design (see Figure 2). In an integrative project design, the project teams start working together on a common goal from the beginning. Individual researchers and/or subprojects have frequent interaction and mutually influence each other and learn together throughout the project process. In doing so they are integrated from the beginning and proceed together towards their common goal (Tress, Tress and Fry 2005). In contrast, the parallel project design involves disciplinary subprojects that run parallel to each other without interaction until late in the project process. Participants try to integrate results in the end, when all disciplinary subprojects have delivered their results. However, this is the phase when most projects run out of time and money and integration proves to be impossible due to incompatibility of the different types of data and knowledge resulting from the disciplinary subprojects. Projects that aspire to integration but make no concrete efforts to reach integration are mostly characterized by a parallel project design.
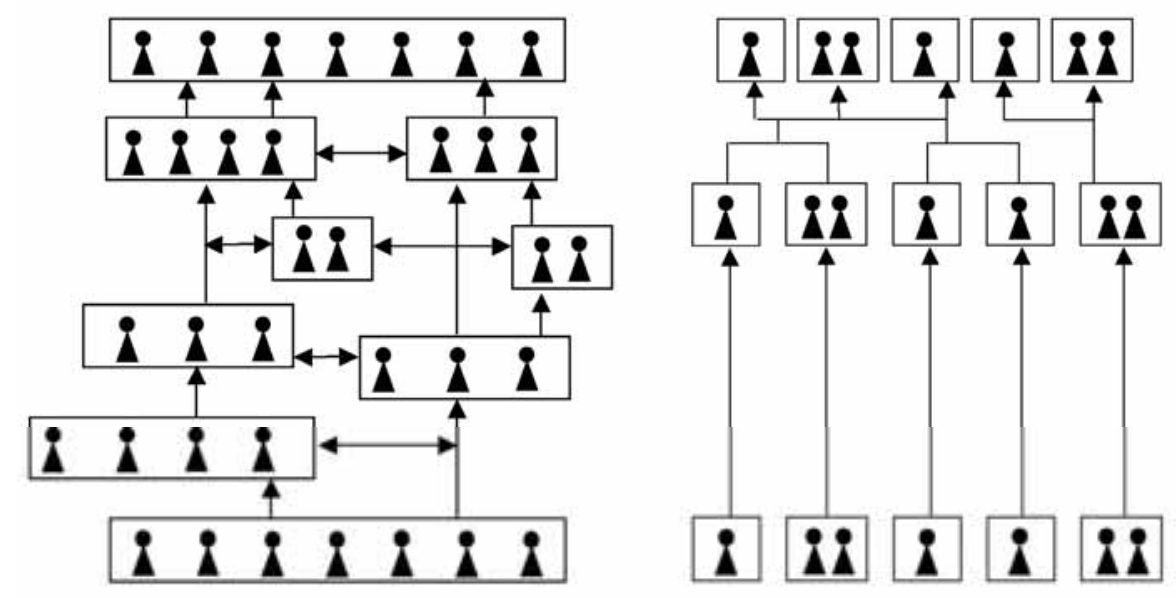

Figure 2. Integrative (left) and parallel (right) project designs

\section{Develop an integration implementation plan}

An integration plan needs a description of the planned progress, its goals and how they will be achieved. Integrative teams should decide on their aims and ambitions for integration early on in projects. Large projects, with different interdisciplinary or transdisciplinary subprojects, need to define whether their integrative actions will take place at the level of the subprojects or at the overarching project level. All aspects of 
integration and how it will be achieved can be formulated in the Integration Implementation Plan. The Integration Implementation Plan can be a written document that is signed by the project participants to confirm agreement. Research is a creative process and the plan may thus need adaptations and refinement throughout the project process to reflect changes of interest, direction and progress; it will, however, remain an important guidance towards success.

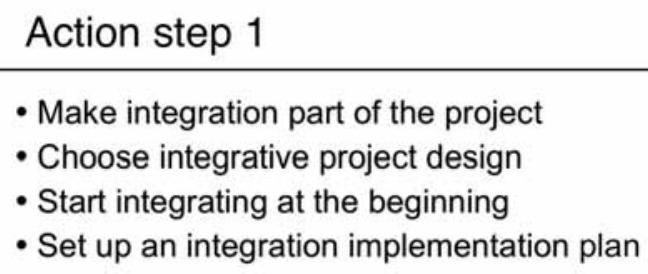

\section{Step 2: Identify common research questions and project goals}

We recommend starting an integrative project with the identification of a clear research question and the formulation of a project goal. The common research goal should be formulated in a way that represents aspects of each participating discipline and is meaningful and of interest to the individual researchers.

Research teams that are able to agree on a common project goal can focus on integrating their different knowledge cultures towards this goal and can reach integration (Daschkeit et al. 2001; Fry 2001). Research teams that cannot agree on a common research question and project goal force the individual participants into disciplinary subprojects. Time is precious, and if agreement on a common research question cannot be reached, participants feel the need to start their research and will tend to do this from their own disciplinary perspective. Defining a common research question for integrative projects can be a difficult task as projects are increasingly initiated by funding agencies to solve real-world problems (e.g. effects of the EU Common Agricultural Policy on land use, sustainable management of coastal areas, strategies to manage natural hazards, effect of climate change (Cortner 2000; Van Asselt and Rijkens Klomp 2002; Tress, Tress and Fry 2005). Research teams need to translate specific environmental concerns into a research question. The projects are expected not only to target the problem solution, but also to make an original contribution to science. We feel that it is very important to find the right balance between aspects of fundamental research, applied research and consultancy in integrative projects. As integrative studies often focus on solving real-world problems, they frequently have a preponderance of applied and consultancy aspects. It is, however, the fundamental part that leads to the creation of new methods and theory and is thus most suitable for publication in high-ranking international journals. Projects that have a good balance between fundamental and applied aspects are more likely to reach success. They do not only solve their practical problem but also gain academic merit and acknowledgement. 


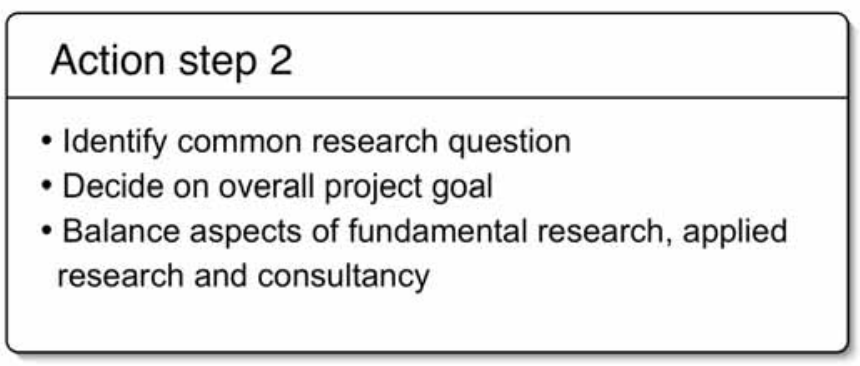

\section{Step 3: Identify project participants and their roles}

\section{Identify relevant disciplines}

The research goals and real-world problems that the project sets out to solve determine which disciplines are needed. Projects that add on disciplines for the sake of it (e.g. to increase chances of funding, bring together friends, etc.) have problems to make integration work, simply because there is no or little purpose and hence hope of a meaningful contribution from some of the disciplinary expertise. So, our advice is to identify the relevant disciplines by asking which expertise we need to solve a given research question. If a research question involves the expertise of only two disciplines (e.g. archaeology and landscape planning to investigate safeguarding of cultural heritage in changing landscapes), this can be a successful cooperation that may not require involvement of more disciplines. Integration becomes increasingly demanding as more disciplines or non-academic stakeholders are involved. If one has no experience with integrative research, we suggest starting with a research question that does not require involvement of more than two or three disciplines.

Another point of consideration is the level of experience of the participants that will be involved. Not all integrative projects are suitable for $\mathrm{PhD}$ students, who frequently face conflicting demands from applied project goals and reaching a disciplinary $\mathrm{PhD}$ (see Chapter 14). As reaching integration is a challenge and academic merit may be difficult to reach, one should consider the involvement of more senior researchers for crucial project tasks, supported by junior staff, who can bring in fresh ideas. We do not recommend the development of projects that only employ $\mathrm{PhD}$ students and a project leader in the project organization. This structure often fails.

\section{Decide upon involvement of non-academic participants}

Many integrative projects involve not only different disciplines (interdisciplinary projects) but also non-academic participants (transdisciplinary projects). 'Nonacademic participants' covers all those that are not participating in the project as academic investigators. These can be local stakeholders, people from planning offices, or members of governmental bodies or non-governmental organizations; it can be everybody whose knowledge one expects to be of benefit to the project. A decision whether or not non-academic participants should be involved in the project should be made in a similar way as for the selection of the academic participants. The research question determines whether or not the participation of non-academic participants is relevant for the project. We recommend involvement of non-academic participants if they can add new perspectives/knowledge for the given research question that could not be gathered otherwise.

When non-academic participants are involved, one needs to define which participants may be most suitable (kind of expertise, kind of organization, how many), 
and the roles they will have in the project (see also Chapter 2). In larger projects, roles of non-academic participants can be formalized as part of the Integration Implementation Plan. We distinguish four different levels of interaction, related to the role of non-academic participants:

a) as informants for the research team

b) as consultants of the research team

c) having real involvement in the research project (equal to academic participants)

d) having control of the project (non-academic participants steer the project process according to their demands and priorities).

Projects that do not define the roles of non-academic participants early in the project can accidentally awake high expectations in them that for many different reasons can never be fulfilled. If not made clear in the project plan, non-academic participants (who sometimes are also a funding agent of the project) may assume they have the right to make decisions related to steering the project or altering the project process or goals.

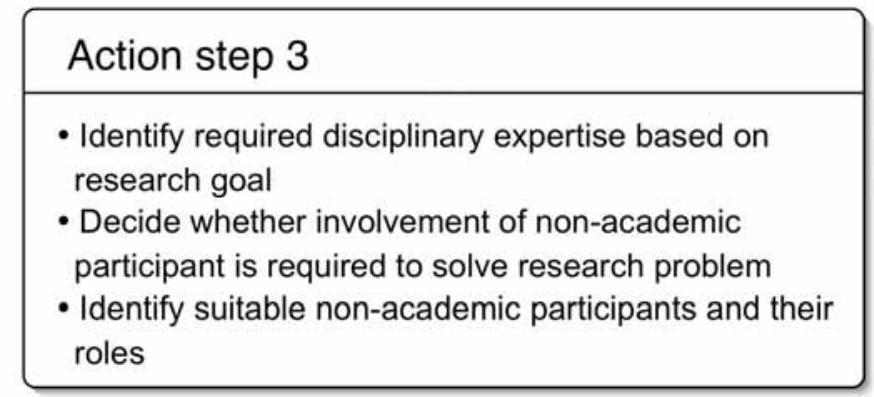

\section{Step 4: Agree on integrative concepts and face the challenge of epistemology}

\section{Agree on a definition of the integrative concept}

For integrative projects it is crucial to find agreement on a definition of the integrative concept. This includes the development of a strategy for how the concepts can be operationalized in the project. We suggest an integrative team to discuss how they understand interdisciplinarity/transdisciplinarity in their respective subprojects. Once agreement is reached, the participants can think about the steps that will be necessary to apply the concept. Both the common definition/understanding and the process of operationalization should be fixed in written form as part of the Integration Implementation Plan (see Step 1).

Discussing and agreeing aspects of the integrative concept and its operationalization is more than a philosophical exercise. If no common agreement is reached, participating researchers may unknowingly have very different expectations towards the project and how integration may be realized. Furthermore, it will be difficult to compare project outcomes with those of other projects if the same terms (e.g. interdisciplinarity) are used but with different meanings (Tress, Tress and Fry in press). Projects that reached a common definition on integrative concepts are perceived as being more successful. It is not important which of the existing definitions of interdisciplinarity/ transdisciplinarity (e.g. Jantsch 1970; 1972; Klein 1990; Mittelstrass 1993; Lattuca 2001; Moran 2002) a project adopts (or whether it decides to develop its own), but what is important is that it actually agrees on a 
concept. We have developed a set of integrative concepts that can be used in the context of landscape research (see Tress, Tress and Fry in press).

\section{Face the epistemological challenge}

Epistemology is the theory of knowledge and also frames what is and what is not justifiable knowledge (Audi 2003). In integrative research there is no way to escape the epistemological challenge as projects, by definition, try to integrate knowledge across disciplinary fields. They try to create an overarching epistemology, one that constitutes legitimate knowledge for all involved disciplines. Each discipline has its own coherent set of tools, methods, procedures, concepts and theories. Disciplines work within a specific framework of beliefs and criteria for truth and validity, which limits the kinds of research questions that can be asked and defines the perspective with which questions are approached.

Some disciplinary gaps can be easier to overcome than others, because they may be more similar in their fundamental assumptions (Winder 2003). Main challenges arise when bridging the gap between disciplines of natural sciences, social sciences, and humanities and arts, respectively. Integration and thus bridging of disciplines appears most frequently during discussions among project participants. Many of the projects we investigated reported that their discussions were sometimes hard and long, but they could not have reached their project goals without them (Tress, Tress and Fry 2005). In that sense it may help those starting on integrated projects to know at the outset that misunderstanding and discussion will arise; they are a natural part of the integration process but are necessary for success.

In order to prepare for the epistemological difficulties, we suggest participants get acquainted with the disciplinary knowledge cultures involved in the project. The project team should study key publications of the respective disciplines and learn about past and emerging paradigms. They should also identify what the main methods of the disciplines are, what constitutes valid knowledge and how they gather and interpret data. It may also help project participants to follow introductory courses offered for undergraduate students or to read the course pensum. It may also be advantageous to organize seminars with invited academics to present the state-of-theart in the major theories and methods in specific disciplines. Even if it is hard to achieve, a grounded understanding of other disciplines is necessary to build new integrative theory and methods across the gaps between different epistemologies.

\section{Plan for development of integrative theory and methods}

It is the development of new integrative theory and methods that qualifies as a successful integrative research project. Without theory and method development - and thus the creation of generic knowledge - the project could be more suitably classified as a participatory project or as consultancy. As science is interested in the nature and behaviour of observable phenomena (Feynman 1998) it seeks knowledge that has relevance and validity beyond a specific context.

There are not many readily available integrative methods or theories. Project teams will thus have to look for overarching theories and concepts that are meaningful to all participants and can be a first step to creation of integrative concepts. We recommend defining small steps that will lead to methodological advancement. It can be a starting point to search for existing concepts or theoretical frameworks that appear interesting to all involved disciplines. Each discipline may have a different interpretation of the concepts in the beginning, but exploring the overlapping conceptual zones offers a rich source for the development of common theory. 


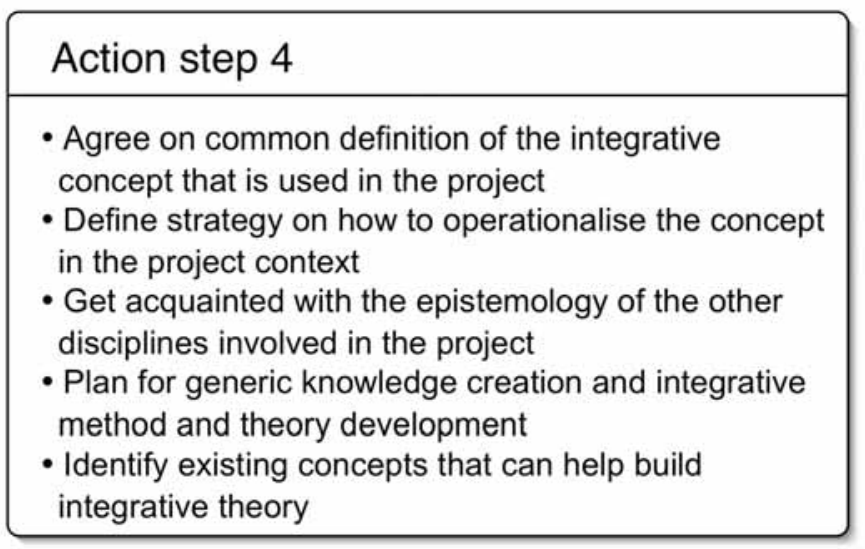

\section{Step 5: Give opportunity for frequent contact in an atmosphere of mutual trust and respect}

\section{Creating a meeting of minds}

Frequent formal and informal contact is crucial for integrative teams, as is a good project atmosphere. Mutual trust, understanding and respect are the preconditions for integrative work (Hollaender, Loibl and Wilts 2002; Kinzig 2001; Persson 1999). Researchers in integrative projects need to have intense contact to create integration and therefore it is necessary that they get along with each other. A prerequisite for this is to agree to the equality of each other's ideas and beliefs and that no discipline is superior to another. In the beginning, projects should plan for special events (common weekend etc.) to get to know each other. We have also evidence that being socially together outside the research project helps team-building and tackling difficult situations. The goal is to create an atmosphere where project participants are not afraid to ask 'stupid' questions. It is one way to get to know the ways other disciplines see the world and to make colleagues aware of what one may not have understood from one's own disciplinary perspective. It is also important to be able to exchange negative feelings such as dissatisfaction, disagreement, disappointment, etc. within the project team. These may uncover important disciplinary differences that need to be overcome.

\section{Arrange for informal and formal meetings}

Results of our web survey revealed that discussions and teamwork were among the most positive experiences of researchers in integrative projects, as they enabled active exchange with other participants. Discussions and joint work are thus the setting where common ground is identified and where integration happens. However, meetings of integrative teams once in a while do not automatically lead to fruitful discussions and joint work. In our interviews, researchers stated that it was problematic that their meetings (often formal) were primarily used for updating progress or to give a state-of-the-art report on the individual subprojects and not specifically to enhance the degree of integration (Tress, Tress and Fry 2005).

Ideally, integrative teams should be placed at one institute for the duration of their project. In reality, this is seldom possible because participants come from different institutes and countries. In this case, well-planned meetings are crucial for reaching integration. An integrative team should at the start of a project agree on a modus for regular formal meetings (e.g. once a week). The meetings need to be prepared and agendas sent to all participants in advance. Decide on a specific purpose for each 
meeting. This might be the discussion of a commonly identified problem area or a recent publication that was found of importance for the project. Besides the regular meetings, there should be meetings upon demand for special purposes (e.g. trainings, meetings with stakeholders, publication workshops, etc.). The demand for more planned and coordinated meetings may also increase with the project size, while small groups may need less steering. For informal meetings, we suggest creating physical room that facilitates spontaneous gatherings and rounds of discussions. Think of refurnishing an office into a common lunchroom or having a sofa and coffeemaker somewhere in the hall, these help creating an informal and relaxed atmosphere.

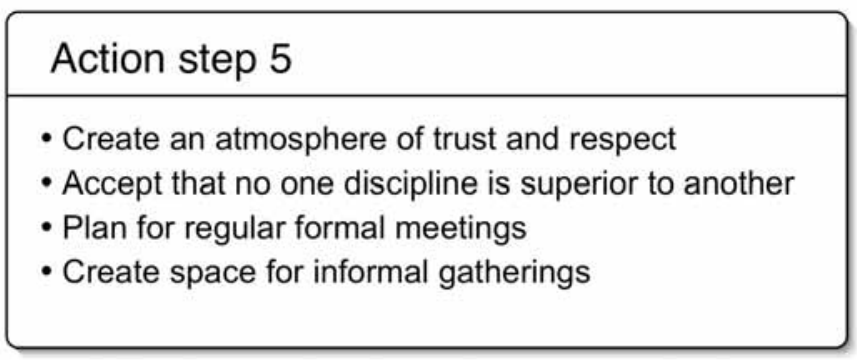

\section{Step 6: Plan for extra time}

There are three main reasons why integrative projects have an additional time demand. All three aspects need to be considered when planning an integrative project:

a) Researchers come together from different disciplines and first have to agree on a common research question and develop a common language.

b) Integrative theory, methods and tools to solve the research question are not readily available, and have to be developed in most cases.

c) Integrative projects are characterized by close interaction and dependencies. The dependencies are related to the joint effort of integrating knowledge from different domains. One participant may have to wait for input (e.g. data from a field survey) from another participant to continue with the work.

We advise working with a time management plan throughout the project process. In such a plan the project leader allocates tasks for each participant, and the participants indicate the time demand of each of their tasks. Participants should break the main tasks down into smaller units, where it is easier to give a realistic time estimate. Extra time buffers need to be calculated for each major task and in general for unforeseen difficulties. For further information on time management in projects see Heerkens (2001) and Young (2002; 2003). Ghant-charts help to make dependencies transparent and to plan researchers' tasks. The time demand is particularly high in the beginning phase of a project. Project leaders should therefore not put too much pressure on participants in the first months and adapt expectations in terms of early outcomes accordingly. 


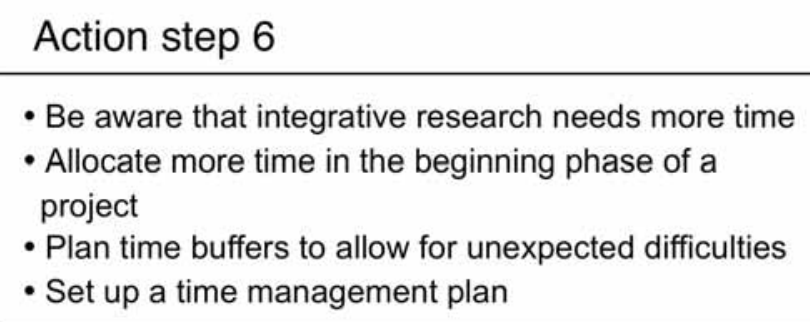

\section{Step 7: Strive for good project leadership and management}

The challenges of integrative research call for leaders with highly developed interpersonal skills, research credibility and ability to maintain the motivation of the team, even when things go wrong. Leaders should be involved in the projects for a major part of their work and have a realistic time budget allocated for the leadership task. Leading a large integrative project is a full-time task on its own. It demands particular skills for creating a good working environment for the research team. The project leader represents the project to the higher organizational structures of the department or university, and is accountable for its outcomes. As the work of integration comes on top of the leadership task, we recommend selecting experienced leaders and give opportunity for specialized leadership training. Michael (1995) documents the importance of good leadership for learning environments. Skilled leaders are more likely to reach a better integration in integrative projects and are better able to respond to external pressure (Persson 1999).

Our web survey showed that 54\% of all leaders had only half of their time or less available for their leadership task $(\mathrm{N}=90)$. Fourteen percent of all leaders had no time available; they had to lead the project in addition to their other tasks. Some of the difficulties that leaders in integrative projects expressed were: pressure from funding bodies, conflict with the academic management (university board, dean, director, etc.), and struggles with the organizational structures of academia (affiliation to and duties for different disciplinary departments).

The success of a project is dependent on the guidance of a good leader, one who ensures that the project budget and time are adequate, facilitates and organizes formal and informal meetings, and takes initiative to formulate the formal project plans.

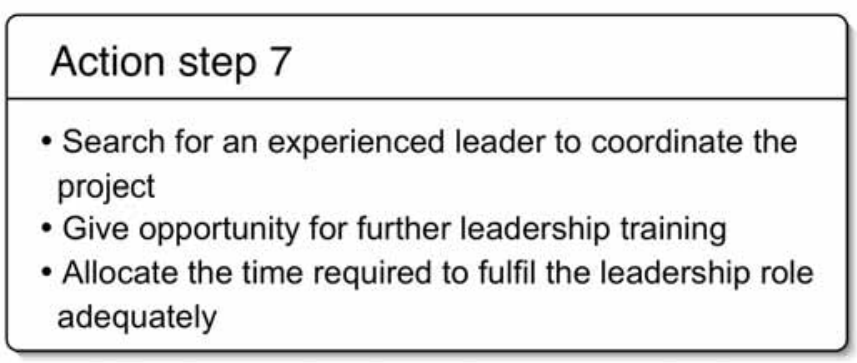

\section{Step 8: Assure support of wider research environment}

This step is considered in relation to the environment in which integrative projects take place. Most integrative projects are conducted at universities or research institutes. While the project participants and the project leader are committed to integrative research, the wider environment, from departments to the board of 
directors, may not be aware of the particular challenges of integrative research. Although widely accepted at many institutes, integrative research is occasionally met with scepticism. This can be a problem especially for project leaders, in terms of both practical and moral support. We therefore suggest seeking agreement and support for integrative projects at higher management levels from the very beginning. It should be clarified how the project goals of the integrative project fit to the overall research strategy and policy of the university/research institute.

A supportive institutional infrastructure is one that supports integrated projects and is willing to accommodate the special requirements of integrative research. This may involve the creation of flexible office spaces to bring researchers from different disciplines (and departments) together for the duration of a project or to give extra financial support due to the higher time demand. Researchers need to feel that integrative studies are appreciated and that their special challenges and problems are acknowledged. We recommend project leaders together with the research managers of their institution to agree on means of quality control for the project. They should further exchange views on their expectations in terms of project outcomes, and develop strategies to link the efforts and achievements of the project to the existing merit system.

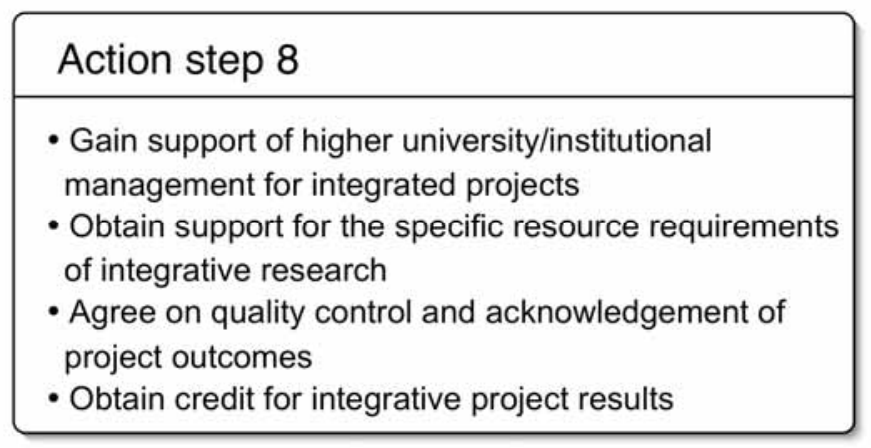

\section{Step 9: Plan for project outcomes, including publications}

\section{Plan for different types of project outcomes}

Project outcomes from integrative projects can be

a) scientific products (publications, method and theory development)

b) product outcomes (methods, tools, guidelines, advice, outputs requested by funding body)

c) outcomes for education and training (number of completed $\mathrm{PhDs}$ and master's degrees, student exchange, courses deriving from the project).

An important criterion for integrative project outcomes is whether the whole outcome is more than the sum of its parts. In other words, true integrative outcomes could not have been produced by any one of the involved disciplines alone, but have emerged from the integrative effort. Project teams need to define what kind of outcomes they will produce and when the outcomes will be delivered. In many cases, particularly for contract research, the outcomes are defined by the funding agency. We suggest that project outcomes should be listed in the Integration Implementation Plan and that sufficient time and resources be allocated for their realization. It is important to define actions that lead to the product development throughout the course 
of a project. It can be good to plan for small products early in the project process, because little successes stimulate and keep up a high level of motivation.

\section{Plan for integrative publications}

Publication from integrative research is very important, as it is the way to communicate results to the wider scientific community and thus enable others to build on existing integrative knowledge (see Tress, Tress and Fry 2003). Furthermore, the current academic merit system relies heavily on peer-reviewed publications in international journals (Forsyth 1999; Reichert, Daniels-Race and Dowell 2002). We recommend that integrative projects make a publication strategy at the start of the project. This strategy will develop into a concrete plan as the project develops. It can finally include the number of publications per participant, and when these will be written and submitted; the target groups (scientific/wider public), and the most suitable and highest ranked media/journals for the selected target groups. The plan also nominates principal authors, who take the lead in writing the respective papers, and the co-authors and their tasks. In the writing phase authors should arrange and plan time for meetings. It may help for a group of authors to go to another place (a nearby conference centre, a mountain cottage) to have a short, but intense writing meeting. It can be difficult to set aside time when everybody is distracted by the usual institutional tasks. Going away makes it easier for everybody to focus on the publication for a few days and the reward is that a paper that otherwise could have taken months may be drafted in a few days.

We recommend that integrative researchers publish regularly and should not wait until the end to write down the results. Many researchers experienced that they run out of time at the end, which means that there often is no time/money left in the project to work on publications. A funding agency that knows that a project was successful in publishing regularly throughout the project is more likely to give a little extra time/money at the end to round off results and papers.

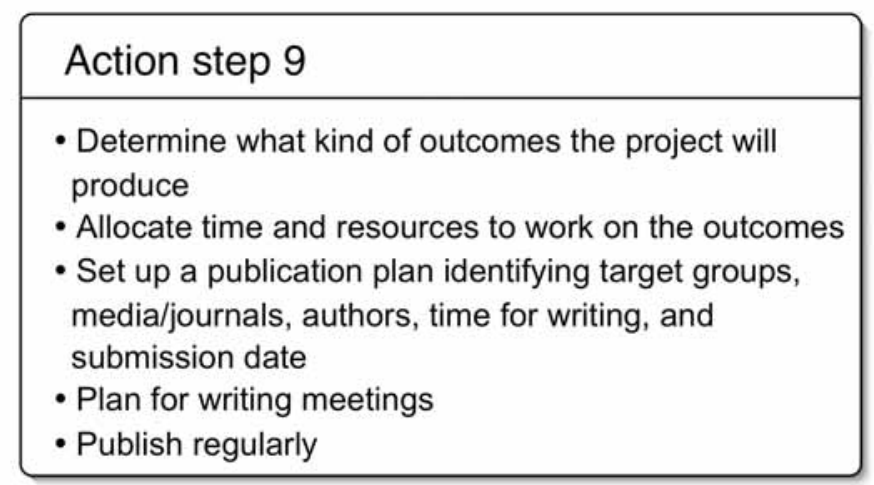

\section{Step 10: Assess individual efforts and project outcomes}

Project assessment is an important tool for project management. An assessment can be used as an instrument by a funding agency to control progress and outcomes according to agreed goals. Participants can also use it to identify what is valued by the funding agency and to assess their progress in the project. There are no welldeveloped criteria for the assessment of integrative projects; most projects are assessed by the application of disciplinary criteria. The applied character of the projects, however, may require an evaluation of practical outcomes and impact in the real world (e.g. capacity/contribution to solve the given real-world problem) as well 
as the standard scientific outcomes. We suggest that evaluation criteria are developed at the start of a project together with the funding agency. The aim should be to clarify the range of criteria that will be used to evaluate the project mid-term and on completion. These should include scientific criteria (number of peer-reviewed publications, presentations at international conferences), practical project impact (e.g. frequency of appearance in the media, knowledge of project among target group, contribution to problem solving), and educational aspects (numbers of finished masters and PhDs, new courses, invitation to lecture at other universities/institutes). Additionally, we suggest assessing the degree of integration that was reached in the project (e.g. number of integrative products that could not have been provided by a single discipline, researchers' perceived degree of integration). If the criteria are clear, assessment can be done as a simple self-assessment (individual researcher/project group) or as peer assessment, with outcomes judged by (external) peers (see Wooding and Grant 2003). We recommend linking the assessment to existing merit systems used at the relevant university/research institute.

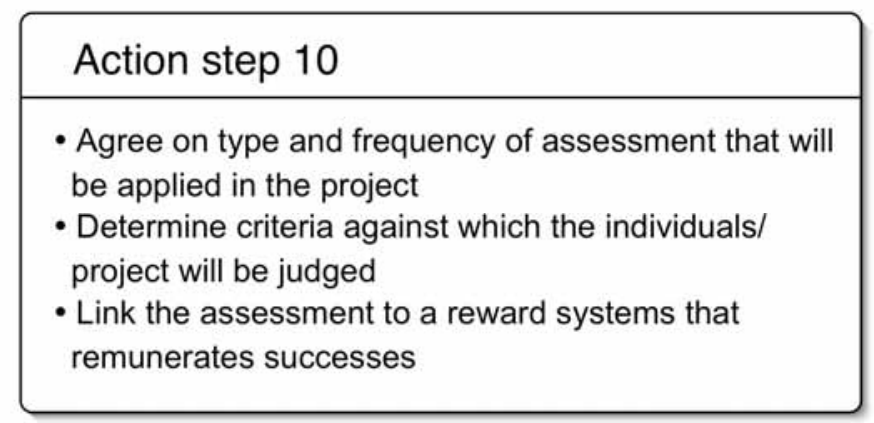

\section{Conclusion}

The ten key steps to success in integrative projects discussed in this chapter and their most important actions are illustrated in Figure 3, to provide a simple overview. What is noticeable is that the most crucial questions determining the success of an integrative project have to be addressed in the initial phase of a project. Research design, selection of participants, agreement on a research question, appointment of a project leader and creation of an atmosphere of trust and respect are, to a large degree, setting the course for the further project development. We can only emphasize the great importance of sound project planning, including all the important aspects. Once determined, many of the mentioned issues are difficult to change. Many problems that appear in projects later on are caused by early mistakes.

If a project starts with many participants who have no experience in integrative research, we suggest looking for or developing training opportunities to provide the necessary skills to cope with the challenges of integrative research. Training for researchers can include the following aspects: development of integrative methods and theory, organizing integration in one's daily project work, coping with differences in knowledge cultures, teamwork, trust building and communication, and publishing. Training specifically for PhD students should include a focus on how to cope with the demands of a disciplinary $\mathrm{PhD}$ while being involved in an integrative project.

Finally, we encourage researchers to feed back their experiences - positive and negative ones - from integrative projects to the wider scientific community. In this way, others can learn from past experiences and avoid unnecessary mistakes. Integrative research is still at an early stage and a lot of effort has to be spent on the 
development of integrative methods and theory, as well as on the operationalization of integration. In this sense every report on how projects have addressed the integrative challenge is valuable knowledge that will over time build a dataset that can lead to successful integrative research. The near future holds the answer to what integrative research can offer and what its limitations are; until that time we are all pioneers with much to gain from pooling our efforts.

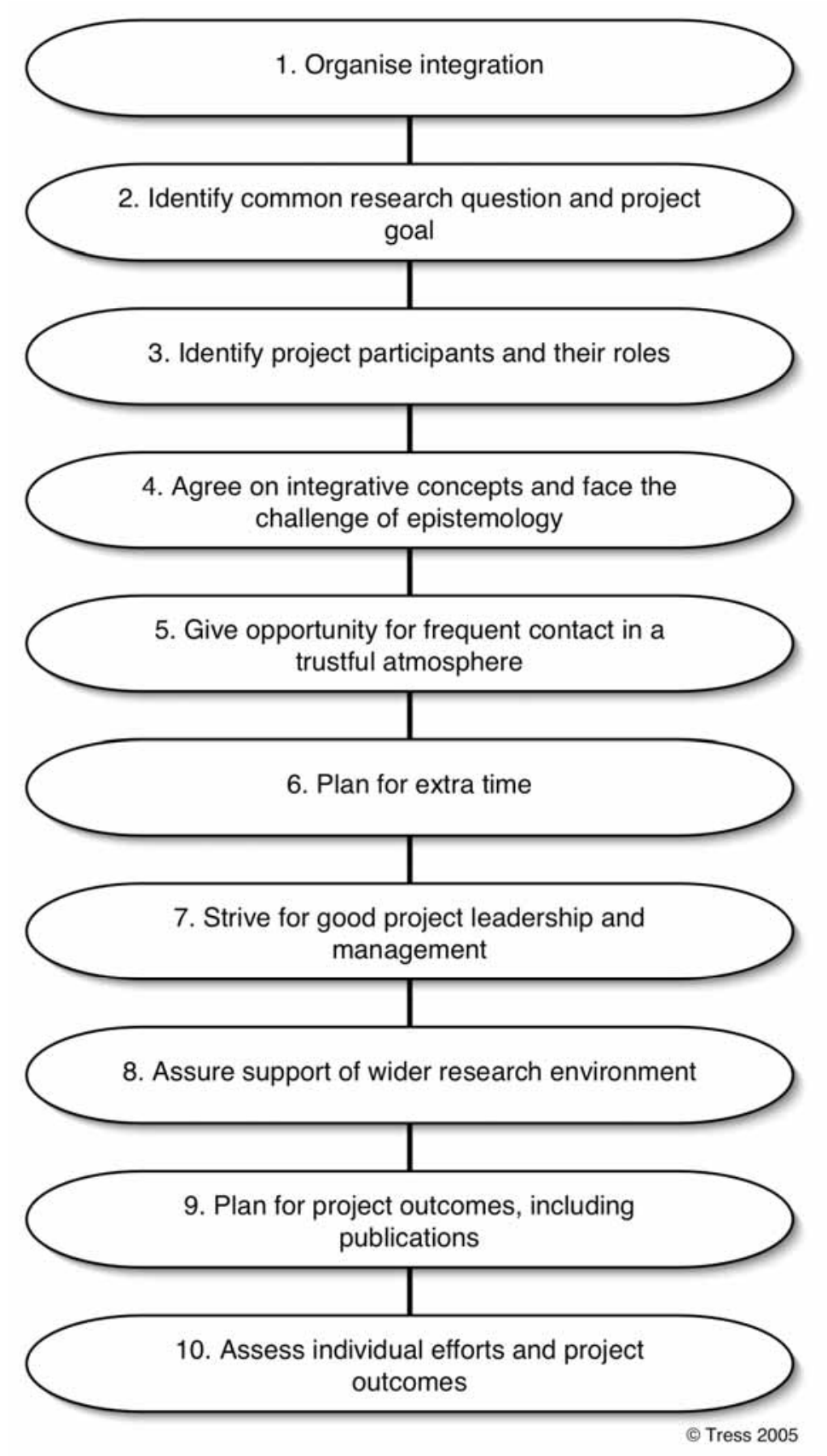

Figure 3. Overview of ten steps to success in integrative research projects

\section{References}

Audi, R., 2003. Epistemology: a contemporary introduction to the theory of knowledge. 2nd edn. Routledge, New York. 
Cortner, H.J., 2000. Making science relevant to environmental policy. Environmental Science \& Policy, 3 (1), 21-30.

Daschkeit, A., Dombrowsky, W.R., Hollaender, K., et al., 2001. Interdisziplinarität in den Umweltwissenschaften: Konzeptionen, Organisation, Erfahrungen. In: Fränzle, O., Müller, F. and Schröder, W. eds. Handbuch der Umweltwissenschaften. 7. Erg.Lfg edn. Ecomed, Landsberg/Lech, 3-24.

Feynman, R.P., 1998. The meaning of it all: thoughts of a citizen scientist. The Penguin Press, London.

Forsyth, A., 1999. On writing and tenure. Journal of Planning Education and Research, 19 (1), 98-105.

Fry, G.L.A., 2001. Multifunctional landscapes: towards transdisciplinary research. Landscape and Urban Planning, 57 (3/4), 159-168.

Heerkens, G.R., 2001. Project management. McGraw-Hill, New York.

Hollaender, K., Loibl, M.C. and Wilts, A., 2002. Management of trandisciplinary research. In: Hadorn Hirsch, G. ed. Unity of knowledge in transdisciplinary research for sustainability. Encyclopedia of Life Support Systems. EOLSS, Oxford.

Jantsch, E., 1970. Inter- and transdisciplinary university: a systems approach to education and innovation. Policy Sciences, 1, 403-428.

Jantsch, E., 1972. Towards interdisciplinarity and transdisciplinarity in education and innovation. In: Apostel, L., Berger, G. and Briggs, A. eds. Interdisciplinarity: problems of teaching and research in universities. O.E.C.D., Paris, 97-121.

Kinzig, A.P., 2001. Bridging disciplinary divides to address environmental and intellectual challenges. Ecosystems, 4 (8), 709-715.

Klein, J.T., 1990. Interdisciplinarity: history, theory, and practice. Wayne State University Press, Detroit.

Lattuca, L.R., 2001. Creating interdisciplinarity: interdisciplinary research and teaching among college and university faculty. Vanderbilt University Press, Nashville.

Michael, D.N., 1995. Barriers and bridges to learning in a turbulent human ecology. In: Gunderson, L., Holling, C.S. and Light, S. eds. Barriers and bridges to the renewal of ecosystems and institutions. Columbia University Press, New York, 461-485.

Mittelstrass, J., 1993. Unity and transdisciplinarity. Interdisciplinary Science Reviews, 18 (2), 153-157.

Moran, J., 2002. Interdisciplinarity. Routledge, London.

Persson, G., 1999. Mistra's role and some lessons learned in the first five years. Policy Sciences, 32 (4), 323-326.

Reichert, W.M., Daniels-Race, T. and Dowell, E.H., 2002. Time-tested survival skills for a publish or perish environment. Journal of Engineering Education, 91 (1), 133-137.

Tress, B., Tress, G. and Fry, G., 2003. Knowledge creation and reflection in integrative and participatory projects. In: Tress, G., Tress, B. and Bloemmen, M. eds. From tacit to explicit knowledge in integrative and participatory research. Alterra, Wageningen, 14-24. Delta Series no. 3.

Tress, B., Tress, G. and Fry, G., 2005. Integrative studies on rural landscapes: policy expectations and research practice. Landscape and Urban Planning, 70 (1/2), 177-191.

Tress, G., Tress, B. and Fry, G., in press. Clarifying integrative research concepts in landscape ecology. Landscape Ecology. 
Van Asselt, M.B.A. and Rijkens Klomp, N., 2002. A look in the mirror: reflection on participation in Integrated Assessment from a methodological perspective. Global Environmental Change Human and Policy Dimensions, 12 (3), 167184.

Winder, N., 2003. Successes and problems when conducting interdisciplinary or transdisciplinary (= integrative) research. In: Tress, B., Tress, G., Van der Valk, A., et al. eds. Interdisciplinarity and transdisciplinarity in landscape studies: potential and limitations. Delta Program, Wageningen, 74-90. Delta Series no. 2.

Wooding, S. and Grant, J., 2003. Assessing research: the researchers' view. Higher Education Funding Council for England. Higher Education Funding Council for England Publication No. MR-1698-HEFCE. [http://www.rareview.ac.uk/reports/assess/AssessResearchReport.pdf]

Young, T., 2002. 30 minutes to plan a project. Kogan Page, London. 30 Minutes Series.

Young, T., 2003. The handbook of project management: a practical guide to effective policies \& procedures. 2nd edn. Kogan Page, London. 